See Article page e261.

\section{Commentary: A multilayered stem cell sandwich?}

\author{
Amit Iyengar, MD, MS, and Pavan Atluri, MD
}

Regenerative tissue therapies for myocardial injury hold great promise for the future of treatment of acute and chronic ischemic heart disease. ${ }^{1,2}$ The discoveries in the past 20 years have occurred at an exciting pace, from discovery of a limited self-regenerating capacity with trans-differentiation of in situ multipotent cells into myocytes, to the ability to harvest and use multipotent cell lines ex situ, to clinical trials using exogenous stem cell therapies for treatment of cardiac injury. ${ }^{2-4}$ Although we have witnessed significant progress in the field, we remain sobered by the impediments in clinical translation. Several key limitations to cell-based therapy for treatment of myocardial injury exist, including durable engraftment and survival of transplanted cells, subsequent cardiomyogenesis, and meaningful improvement in functional outcomes.

In this issue of the Journal, Kashiyama and colleagues ${ }^{5}$ explored the use of a composite tissue-engineered patch of adipocyte-derived stem cells (ADSCs) to ischemic myocardium. The developed multilayered patch consisted of a sandwich of harvested, prepared ADSCs in a sheet, a biodegradable polymer layer (poly(ester carbonate urethane) urea), and a porcine decellularized cardiac extracellular matrix hydrogel. In a subacute rat left ventricular infarct model, they applied this composite patch to injured myocardium and after an 8-week period, observed improved function, greater ADSC engraftment and periinfarct neovascularization, less pathologic interstitial fibrosis, and more endogenous cell infiltration than ADSC or polymer patches alone or sham controls. They conclude

\footnotetext{
From the Division of Cardiovascular Surgery, Department of Surgery, Hospital of the University of Pennsylvania, Philadelphia, $\mathrm{Pa}$.

Disclosures: The authors reported no conflicts of interest.

The Journal policy requires editors and reviewers to disclose conflicts of interest and to decline handling or reviewing manuscripts for which they may have a conflict of interest. The editors and reviewers of this article have no conflicts of interest.

Received for publication May 1, 2020; revisions received May 1, 2020; accepted for publication May 3, 2020; available ahead of print May 15, 2020.

Address for reprints: Pavan Atluri, MD, Division of Cardiovascular Surgery, Hospital at the University of Pennsylvania, 3400 Spruce St, 6 Silverstein, Philadelphia, PA 19104 (E-mail: Pavan.atluri@uphs.upenn.edu).

J Thorac Cardiovasc Surg 2022;163:e273-4

$0022-5223 / \$ 36.00$

Copyright (c) 2020 by The American Association for Thoracic Surgery

https://doi.org/10.1016/j.jtcvs.2020.05.020
}

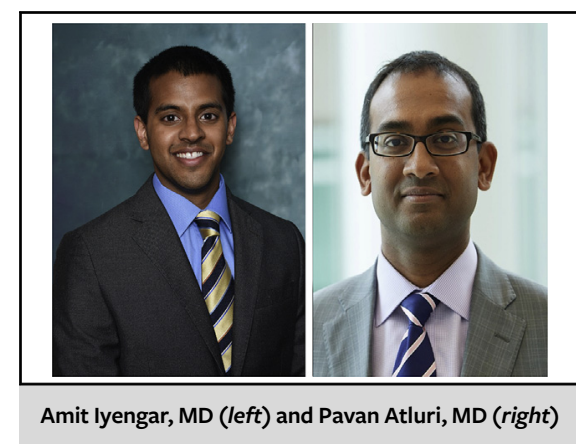

CENTRAL MESSAGE

In a subacute rat infarction

model, the current authors have

used a patch layer adipose-

derived stem cells and biode-

gradable polymer, with improved

function and remodeling

compared with controls.

that a combined patch approach may be superior in realizing the benefits of stem-cell therapy than the components alone.

Each component of the authors' developed patch has been shown in previous studies to separately improve function and remodeling in small animal models following acute infarction. ${ }^{6-8}$ However, important in the current study is the improvement in engraftment after 8 weeks, significantly greater when the ADSC sheets were combined with additional layers. Much of the benefits of ADSCs in previous works have been attributed more to the paracrine signaling effects of these cells in triggering angiogenesis, rather than in situ transdifferentiation. ${ }^{2}$ With more viable cells at a later period, the beneficial paracrine signaling mechanisms can continue and provide more time for putative endogenous cardiomyogenesis or translocation of subsequently differentiated ADSCs into the damaged myocardium. The combined approach in the current study had more endogenous inflammatory infiltration into the patch than any one component alone, and it remains unknown whether this will promote or hinder longer-term remodeling. Furthermore, translatability to larger animal models and ultimately humans will be an important hurdle still limiting otherwise promising results in small animal models. ${ }^{1}$

We applaud Kashiyama and colleagues for continuing to move the field of stem cell therapies forward. The concept of combining multiple components of tissue engineering 
will undoubtedly be necessary in achieving meaningful translation to human disease, and the authors take an important step in that direction. With steady work, the dream of true cardiac regenerative therapy may one day be fully realized. The authors have made a fine sandwich, and we cautiously await the next course.

\section{References}

1. Pavo N, Charwat S, Nyolczas N, Jakab A, Murlasits Z, Bergler-Klein J, et al. Cell therapy for human ischemic heart disease: critical review and summary of the clinical experiences. J Mol Cell Cardiol. 2014;75:12-24.

2. Zuk PA, Zhu M, Ashjian P, De Ugarte DA, Huang JI, Mizuno H, et al. Human adipose tissue is a source of multipotent stem cells. Mol Biol Cell. 2002;13: 4279-95.

3. Beltrami AP, Urbanek K, Kajstura J, Yan SM, Finato N, Bussani R, et al. Evidence that human cardiac myocytes divide after myocardial infarction. $N$ Engl J Med. 2001;344:1750-7.
4. Bergmann O, Bhardwaj RD, Bernard S, Zdunek S, Barnabé-Heider F, Walsh S, et al. Evidence for cardiomyocyte renewal in humans. Science. 2009;324: 98-102.

5. Kashiyama N, Kormos R, Matsumura Y, D'Amore A, Miyagawa S, Sawa Y, et al. Adipose-derived stem cell sheet under an elastic patch to improve cardiac function in rats after myocardial infarction. J Thorac Cardiovasc Surg. 2022; 163:e261-72.

6. Hashizume R, Fujimoto KL, Hong Y, Guan J, Toma C, Tobita K, et al. Biodegradable elastic patch plasty ameliorates left ventricular adverse remodeling after ischemia-reperfusion injury: a preclinical study of porous polyurethane material in a porcine model. J Thorac Cardiovasc Surg. 2013;146:391-9.

7. Yoshizumi T, Zhu Y, Jiang H, D’Amore A, Sakaguchi H, Tchao J, et al. Timing effect of intramyocardial hydrogel injection for positively impacting left ventricular remodeling after myocardial infarction. Biomaterials. 2016; 83:182-93.

8. Kutschka I, Chen IY, Kofidis T, Arai T, von Degenfeld G, Sheikh AY, et al. Collagen matrices enhance survival of transplanted cardiomyoblasts and contribute to functional improvement of ischemic rat hearts. Circulation. 2006; 114:1167-73
See Article page e261.

\section{Commentary: Cardinal virtues of multifarious hydrogel implant in cardiac resurrection}

Finosh G. Thankam, PhD, and

Devendra K. Agrawal, PhD (Biochem), PhD (Med

Sci), MBA, MS(ITM), FAAAAI, FAHA, FAPS, FIACS

Permeant loss of cardiomyocytes, the "beating elements," in the myocardium following myocardial infarction (MI) leads to irreversible cardiac damage, suggesting the need for myocardial restoration and regeneration to rescue the cardiac function. ${ }^{1}$ Even though the existing management

From the Department of Translational Research, Western University of Health Sciences, Pomona, Calif.

The research work of D. K. Agrawal is supported by National Institutes of Health Research Grants R01 HL128063, R01 HL144125, and R01HL147662. The content of this article is solely the responsibility of the authors and does not necessarily represent the official views of the National Institutes of Health.

Disclosures: The authors reported no conflicts of interest.

The Journal policy requires editors and reviewers to disclose conflicts of interest and to decline handling or reviewing manuscripts for which they may have a conflict of interest. The editors and reviewers of this article have no conflicts of interest.

Received for publication May 2, 2020; revisions received May 2, 2020; accepted for publication May 3, 2020; available ahead of print May 15, 2020.

Address for reprints: Devendra K. Agrawal, PhD (Biochem), PhD (Med Sci), MBA, MS(ITM), FAAAAI, FAHA, FAPS, FIACS, Department of Translational Research, Western University of Health Sciences, 309 E. Second St, Pomona, CA 91766-1854 (E-mail: DAgrawal@WesternU.edu).

J Thorac Cardiovasc Surg 2022;163:e274-6

$0022-5223 / \$ 36.00$

Copyright (c) 2020 by The American Association for Thoracic Surgery

https://doi.org/10.1016/j.jtcvs.2020.05.012
Check for updates

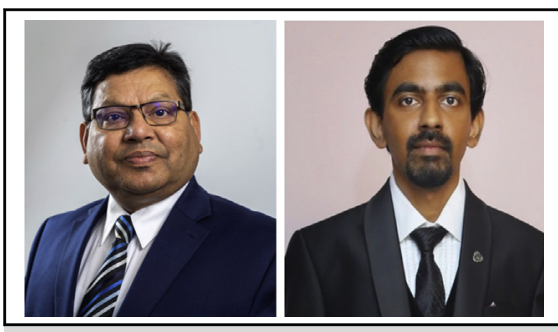

Devendra K. Agrawal, PhD (Biochem), PhD (Med SCi), MBA, MS(ITM), FAAAAI, FAHA, FAPS, FIACS, and Finosh G. Thankam, PhD

CENTRAL MESSAGE

The combinatorial approach of

hybrid hydrogels decorated with

ADSC sheets significantly im-

proves myocardial regeneration

following acute myocardial

infarction.

strategies have been successful in preventing early mortality, protecting the surviving myocardium and reducing the further threat of cardiac arrest, the approaches for the replacement and rejuvenation of cardiac cells in the infarct zone to accelerate the regeneration of a functional myocardium remains to be achieved. ${ }^{2}$ For instance, we recently reported that approximately $50 \mathrm{~g}$ of an injured myocardium reflects the irreversible loss of $\sim 1$ billion cardiomyocytes 